\title{
Global nonlinear optimization for the interpretation of source parameters from total gradient of gravity and magnetic anomalies caused by thin dyke
}

\author{
Arkoprovo Biswas ${ }^{1,{ }^{\star}}$, Mahesh Prasad Parija ${ }^{1}$, Sushil Kumar ${ }^{1}$ \\ ${ }^{1}$ Wadia Institute of Himalayan Geology (WIHG), Dehradun, Uttarakhand, India
}

\author{
Article history \\ Received August 5, 2016; accepted December 12, 2016. \\ Subject classification: \\ Gravity and Magnetic anomaly, dyke-type structure, VFSA, Uncertainty estimation, ore exploration.
}

\begin{abstract}
An efficient approach to estimate model parameters from total gradient of gravity and magnetic data based on Very Fast simulated Annealing (VFSA) is presented. This is the first time VFSA has been applied in interpreting total gradient of potential field data with a new formulation estimation caused due to isolated causative sources embedded in the subsurface. The model parameters interpreted here are the amplitude coeffcient $(k)$, exact origin of causative source $\left(x_{0}\right)$ depth $\left(z_{0}\right)$ and the shape factors (q). The results of VFSA optimization show that it can uniquely determine all the model parameters when shape factor is controlled to its actual value. The model parameters estimated by the present method, mostly the shape and depth of the buried structures were found to be in excellent agreement with the actual parameters. The method has also the proficiency of evading highly noisy data points and improves the interpretation results. Study of histogram and cross-plot analysis also suggests the interpretation within the estimated uncertainty. Inversion of noise-free and noisy synthetic data for single structures as well as field data demonstrates the efficacy of the approach. The technique is warily and effectively applied to real data examples (Leona Anomaly, Senegal for gravity, Pima copper deposit, USA and Matheson area, Northern Ontario, Canada for magnetic/aeromagnetic data) with the presence of ore bodies. The present method can be extremely applicable for mineral exploration or ore bodies of dyke-like structure embedded in the shallow and deeper subsurface. The computation time for the whole process is very small.
\end{abstract}

\section{Introduction}

Gravity and Magnetic surveying has been extensively used over the years to map regional geological structures, basin researches, especially through the reconnaissance and analysis of anomalies. Moreover, it has been widely used in different branches of earth science studies such as mineral exploration, hydrogeological, environmental studies, geodesic, seismological studies, isostatic com- pensation, subsurface cavity detection, archaeo-geophysics, glacier thicknesses, subsurface modelling and engineering applications as well [Telford et al. 1990, Reynolds 1997, Kearey et al. 2002, Jacoby and Smilde 2009, Hinze et al. 2013]. The idea is based on measuring the variations in the Earth's gravitational as well as magnetic field due to the effects of anomalous density and magnetic susceptibility differences between the subsurface rocks [Al-Garni 2013, Ekinci et al. 2013, Pallero et al. 2015, Ekinci and Yiğitbaş 2015]. Within those investigations cited above, mineral or ore explorations take a significant place because of the economic reasons. Evaluation of the depth of such anomalous buried bodies from the gravity, magnetic and other geophysical or multi-parametric data has drawn significant consideration in exploration of minerals [Mandal et al. 2015, 2013, Biswas et al. 2014a, b]. The isolated gravity and magnetic anomaly due to single ore body is commonly interpreted in terms of few model parameters such as location, source geometry, depth and shape [Roy et al. 2000, Essa 2007, Biswas 2015, Biswas 2016b]. To interpret the different parameters of the estimated structure, numerous interpretation methods was developed. Assuming a fixed simple geometry, various methods was developed for determining some model parameters of the gravity and magnetic sources.

The techniques include graphical methods [Nettleton 1962, 1976], curves matching standardized techniques [Gay 1963, 1965, McGrath and Hood 1970], Monograms [Prakasa Rao et al. 1986], characteristic points and distance approaches [Grant and West 1965, Abdelrahman 1994], ratio methods [Bowin et al. 1986, Abdelrahman et al. 1989], neural network [Elawadi et 
al. 2001], Fourier transform [Odegard and Berg 1965, Bhattacharyya 1965, Sharma and Geldart 1968], Euler deconvolution [Thompson 1982], Mellin transform [Mohan et al. 1986], Hilbert transforms [Mohan et al. 1982], least squares minimization approaches [Gupta 1983, Silva 1989, McGrath and Hood 1973, Lines and Treitel 1984, Abdelrahman 1990, Abdelrahman et al. 1991, Abdelrahman and El-Araby 1993, Abdelrahman and Sharafeldin 1995a], Werner deconvolution [Hartmann et al. 1971, Jain 1976, Kilty 1983]; Walsh Transformation [Shaw and Agarwal 1990], Continual least-squares methods [Abdelrahman and Sharafeldin 1995b, Abdelrahman et al. 2001a, b, Essa 2012, 2013], Euler deconvolution method [Salem and Ravat 2003], Fair function minimization procedure [Tlas and andAsfahani 2011a, Asfahani and Tlas 2012], DEXP method [Fedi 2007], deconvolution technique [Tlas and Asfahani 2011b]; Regularised inversion [Mehanee 2014, Mehanee and Essa 2015]; Simplex algorithm [Tlas and Asfahani 2015], simulated annealing methods [Gokturkler and Balkaya 2012], Very fast simulated annealing [Biswas and Acharya 2016, Biswas and Sharma 2016a, b; Biswas 2015, Biswas and Sharma 2015, Biswas and Sharma 2014a, b, Sharma and Biswas 2013a], particle swarm optimization [Singh and Biswas 2016] and Differential Evolution [Ekinci et al. 2016] have been used to solve similar kind of non-linear inversion problems for different types of subsurface structures. Also, there are different interpretation methods for gravity and magnetic data that can be found in different literatures [Abdelrahman et al. 2015, 2012, 2009, 2007, 2006, 2005, 2003, 1996, 1994, Asfahani and Tlas 2007, 2004, Tlas et al. 2005]. Amongst several interpretation methods mentioned above, mostly inverse modelling processes aim to best appraisal of the model parameters whose responses are similar to the measured data. In this way, the fittings between the observed and modeled anomalies can be investigated. However, the well-known non-unique, non-linear problem and ill-posed nature of the potential field data inversion makes the processing and interpretation rather difficult. Hence, the inverse modelling problem of potential field anomalies strongly require some constraints in order to recover interpretable and realistic model solutions [Last and Kubik 1983, Li and Oldenburg 1996, 1998, Ekinci 2008, Zhdanov 2009, Feng et al. 2014, Biswas 2015, Biswas 2016, Ekinci et al. 2016]. However, in most of the cases, the measured potential field anomaly was interpreted for residual anomalies.

The objective of the present work is to develop an integrated approach for quantitative interpretation of gravity and magnetic fields over dyke like structure fulfilling Laplace's condition. This procedure is based on the calculation of first order horizontal and vertical derivatives of the observed gravity and magnetic anomaly. The square root of the sum of the squares of these derivatives [horizontal and vertical] is called as Total Gradient [TG] and is identical with the amplitude of the analytical signals [Nettleton 1971, Nabighian 1972, Nabighian et al. 2005a, b]. A detailed explanation about the TG is explained in Appendix I. Further, to develop the method, a variant of Simulated Annealing [SA], called as Very Fast Simulated Annealing [VFSA] is used to determine the various model parameters related to thin dyke type structures for TG of gravity and magnetic anomalies. This algorithm has a competence to escape local minima by performing a stochastic search within the model space and does not require well-constructed initial model providing a robust and versatile search processes without negotiating the resolution [Sen and Stoffa 2013, Sharma and Kaikkonen 1998, 1999a, b, Sharma and Biswas 2011, Sharma 2012, Sharma and Biswas 2013a, b, Biswas and Sharma 2015, Biswas and Sharma 2016a, b, Biswas, 2016a] and is used in interpreting the TG of gravity and magnetic anomaly data. The application of the proposed technique is performed with the help of synthetic data and two examples from Leona Anomaly, South Saint-Louis, Western Coastline, Senegal and Pima Copper deposit, Arizona, USA from ground based survey and one magnetic anomaly from Matheson area, Northern Ontario, Canada from aeromagnetic survey. The method can be used to interpret the gravity and magnetic anomalies occurred due to thin dyke-type mineralized bodies.

\section{Methodology}

\subsection{Mathematical Formulation for Forward Modeling}

The general expression of a TG of gravity and magnetic anomaly $V(x)$ for thin dyke at any point on the surface (Figure 1) is given by the equations [after Abdelrahman et al. 2001a, b, Srivastava et al. 2014]:

$$
V(x)=k\left[\frac{1}{\left[\left(x-x_{0}\right)^{2}+(z)^{2}\right]^{q}}\right]
$$

where, $k$ is the amplitude coefficient, $z$ is the depth from the surface to the top of the body (Thin Dyke), $x_{0}(\mathrm{i}=1, \ldots, \mathrm{N})$ is the horizontal position coordinate, $q$ is the shape factor. The $q$ value for gravity and magnetic anomaly is 0.5 and 1.0 respectively. The detailed derivation of mathematical formulations can be found in Nettleton [1971], Nabighian [1972], Srivastava and Agarwal [2010], Srivastava et al. [2014]. For brevity, 


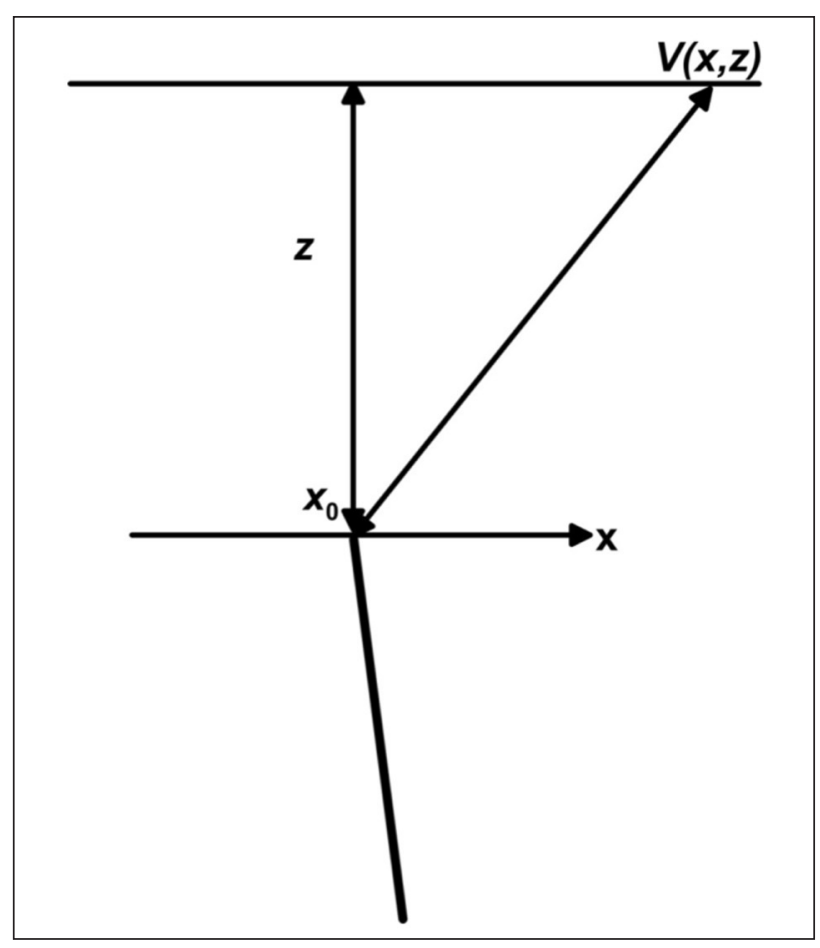

Figure 1. A diagram showing cross-sectional views, geometries and parameters for thin dyke-type structure.

the derivation is not discussed here and is shown in the Appendix II.

For multiple structures, the equation can be written as [Biswas and Sharma, 2014a]:

$$
V\left(x_{i}\right)=\sum_{j=1}^{M} V_{j}\left(x_{i}\right)
$$

where $V_{j}\left(x_{i}\right)$ is the gravity or magnetic anomaly at $x_{i}$ location for $j^{\text {th }}$ body and $M$ is the number of bodies.

\subsection{Inversion method: Very Fast Simulated Annealing} Global Optimization

Different conventional least-squares approaches are mainly used for potential field inverse problems. However, in present days, the problems in least-square approaches were overcome by metaheuristic algorithms which do not require good initial estimates to reach the global minimum. Such metaheuristic algorithm or now-a-days the global optimization methods such as simulated annealing, genetic algorithms, artificial neural networks, particle swarm optimization and Differential Evolution have been used in various geophysical data sets [e. g., Rothman 1985, 1986, Dosso and Oldenburg 1991, Sen and Stoffa 2013, Sharma and Kaikkonen 1998, 1999a, b, Zhao et al. 1996, Juan et al. 2010, Sharma and Biswas 2011, Sharma 2012, Sharma and Biswas 2013a, b, Biswas and Sharma 2014a, Biswas and Sharma 2014b, Biswas and Sharma 2015, Biswas 2015, Singh and Biswas 2016, Ekinci et al. 2016]. The basic idea of Very Fast Simulated Annealing (VFSA) is a global optimization method; the process of chemical thermodynamics where heating a solid in a heat bath and then slowly allowing it to cool down and anneal into a state of minimum energy. The main advantage of VFSA over other methods is its flexibility and its ability to approach global optimality. It has the ability to avoid becoming trapped in local minima, high resolution, and fast computation as well as less memory [Ingber and Rosen, 1992]. The main difference between SA and VFSA is the faster cooling schedule in VFSA due to a sharper Cauchy probability distribution for the random selection of model parameters. Further, SA takes samples at the predefined interval that limits the model resolution, while VFSA can take any value in the model space and increase resolution. Further, VFSA does not remember all models in the optimization process, and hence needs very small memory. Further detailed explanation can be found in various literatures [Sharma and Biswas 2011, Sen and Stoffa 2013, Sharma and Biswas 2013a]. The same principal is used in geophysical inversion which aims to minimize an objective function called error function or the misfit. The error function is analogous to the energy function in a way that error function is directly proportional to the degree of misfit between the observed data and the modeled data. In the present study, the misfit $(\varphi)$ between the observed and model response is used for potential field data interpretation [after Sharma and Biswas 2013a].

$$
\varphi=\frac{1}{\mathrm{~N}} \sum_{\mathrm{i}=1}^{\mathrm{N}}\left(\frac{\mathrm{V}_{\mathrm{i}}^{0}-\mathrm{V}_{\mathrm{i}}^{\mathrm{c}}}{\left|\mathrm{V}_{\mathrm{i}}^{0}\right|+\left(\mathrm{V}_{\text {max }}^{0}-\mathrm{V}_{\text {min }}^{0}\right) / 2}\right)^{2}
$$

Where $\mathrm{N}$ is number of data point, $V_{i}^{0}$ and $V_{i}^{\mathrm{c}}$ are the $i^{\text {th }}$ observed and model responses and $V_{\max }^{0}$ and $V_{\min }^{0}$ are the maximum and minimum values of the observed response respectively.

The details of the inversion process can be found in different literatures such as Sen and Stoffa [2013], Sharma [2012] and Sharma and Biswas [2013], Biswas [2015], Biswas [2013]. In the present VFSA optimization process, parameters such as Initial temperature 1.0 , cooling schedule 0.4 , number of iterations 2000 and number of moves per temperature 50 is used in the present study. Next, to find the global model, Probability Density Function (PDF) and Uncertainty analysis, it has been done based on the procedures established by Mosegaard and Tarantola [1995], Sen and Stoffa [1996].

This code is developed in Window 7 environment using MS FORTRAN Developer studio on a simple 

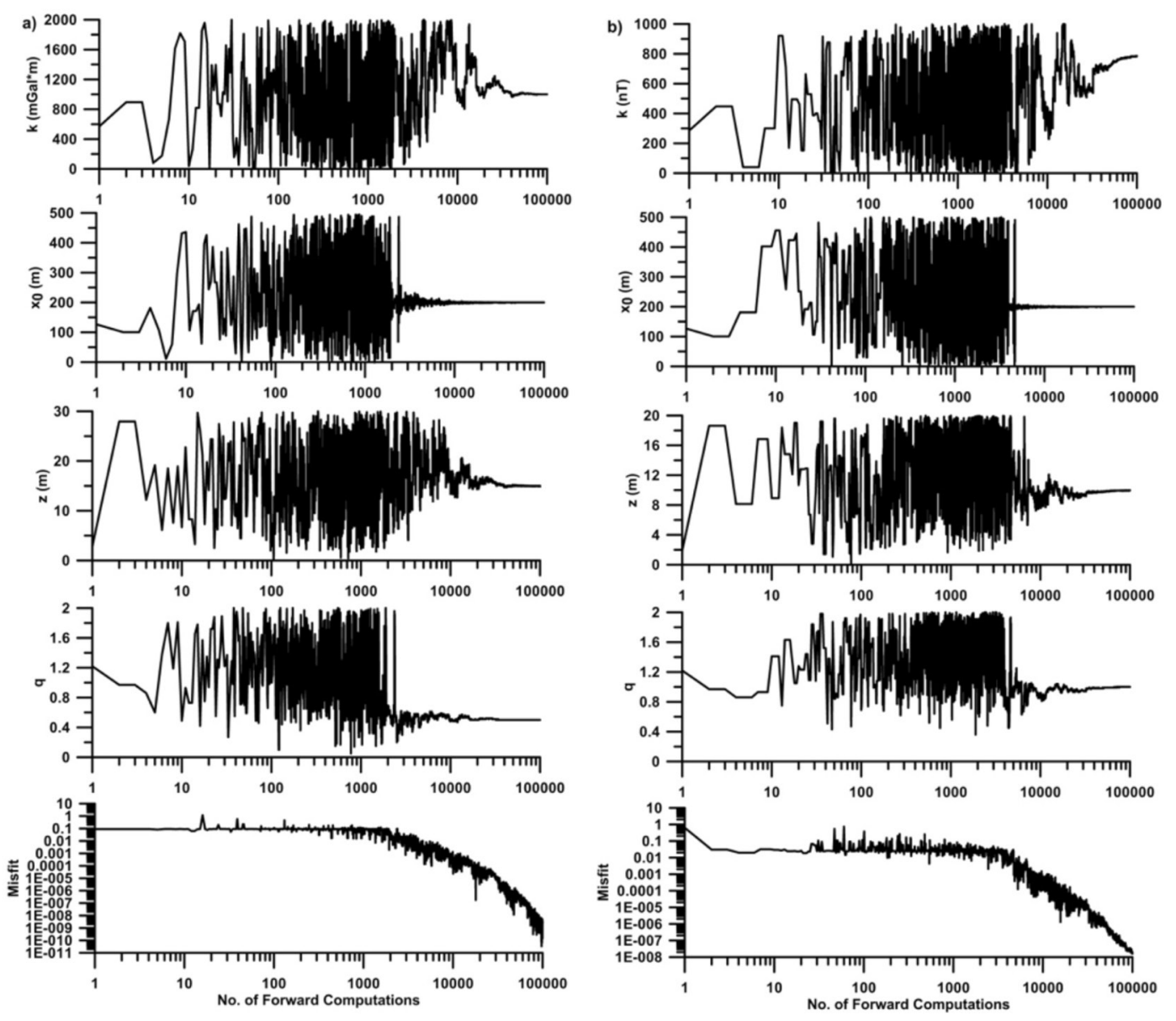

Figure 2. Convergence Pattern for various model parameters and misfit for (a) gravity data and (b) magnetic data.
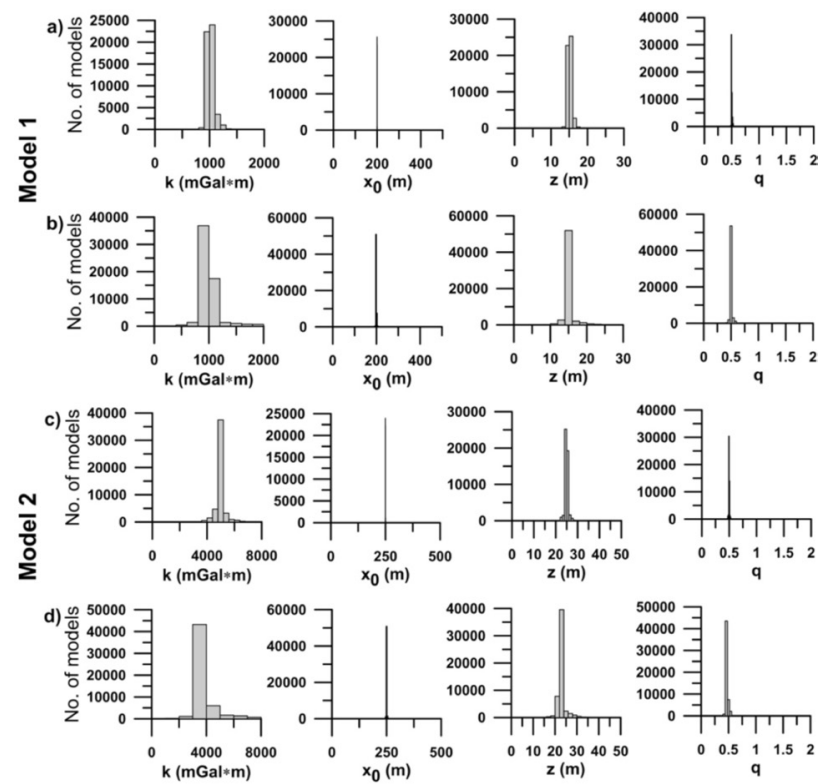

Figure 3. Gravity Data: (a) Histograms of all accepted models having misfit $<10^{-4}$ for noise-free synthetic data when $q$ is uncontrolled (b) Histograms of all accepted models having misfit $<10^{-2}$ for noisy synthetic data ( $10 \%$ Random) when $q$ is uncontrolled for thin dyke-Model 1 , (c) Histograms of all accepted models having misfit $<10^{-4}$ for noise-free synthetic data when $q$ is uncontrolled (b) Histograms of all accepted models having misfit $<10^{-2}$ for noisy synthetic data $(20 \%$ Gaussian) when $q$ is uncontrolled for thin dyke-Model 2.
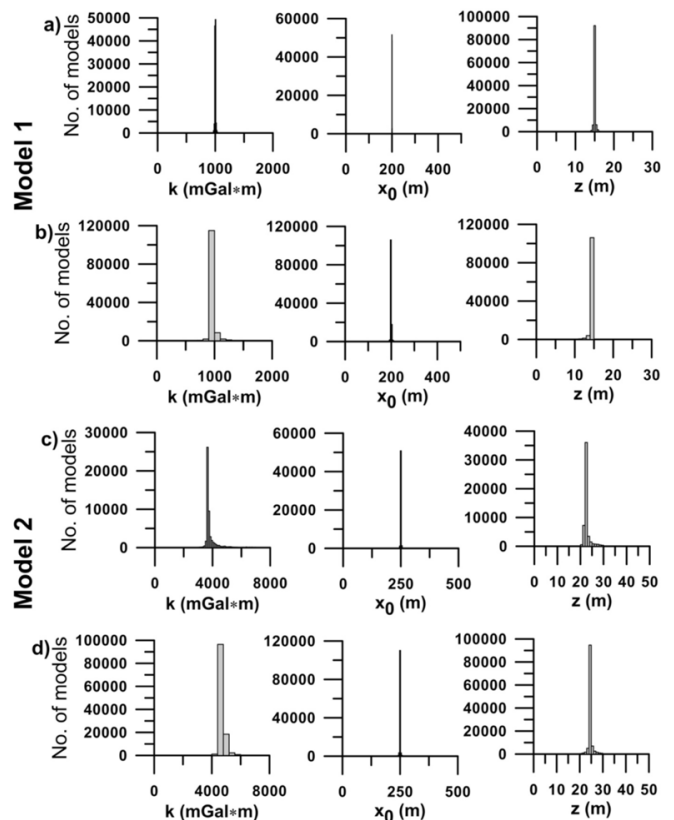

Figure 4. Gravity Data: (a) Histograms of all accepted models having misfit $<10^{-4}$ for noise-free synthetic data when $q$ is controlled (b) Histograms of all accepted models having misfit $<10^{-2}$ for noisy synthetic data ( $10 \%$ Random) when $q$ is controlled for thin dyke-Model 1, (c) Histograms of all accepted models having misfit $<10^{-4}$ for noise-free synthetic data when $q$ is controlled (b) Histograms of all accepted models having misfit $<10^{-2}$ for noisy synthetic data (20\% Gaussian) when $q$ is controlled for thin dyke-Model 2. 
desktop PC with Intel Core i7 processor. For each step of optimization, a total of $10^{6}$ forward computations (2000 iteration $\times 50$ number of moves $\times 10$ VFSA runs) are performed and accepted models stored in memory. The total time taken to complete a single inversion is 35 seconds.

\section{Results and Discussion}

\subsection{Synthetic Example}

The VFSA global optimization is used considering noise-free and noisy synthetic data (10\% Random noise and $20 \%$ Gaussian noise) for gravity and magnetic anomaly over a thin dyke-type model. Initially, all model parameters are optimized for each data set. The general interpretation for both gravity and magnetic method using VFSA is applied for all synthetic and field examples. At first, synthetic data is generated using Eq. (1) for a dyke-model and 10\% Random and 20\% Gaussian noise is added to the synthetic data. VFSA inversion is employed using noise-free and noisy synthetic data to recover the actual model parameters and study the effect of noise on the interpreted model parameters. Principally, a suitable search range for each model parameter is selected and a single VFSA optimization is executed. Afterward the proper convergence of each model parameter is studied $\left(k, x_{0}, z\right.$, and $\left.q\right)$ and misfit by adjusting VFSA parameters (such as initial temperature, cooling schedule, number of moved per temperature and number of iterations). Next, to access the reliability of the method and to get mean model, 10 VFSA runs are performed. Then, histograms are prepared using accepted models whose misfit is lower than $10^{-4}$. Next, a statistical mean model was computed using models that have misfit lower than $10^{-4}$ and lie within one standard deviation. Moreover, cross-plots are also studied to check whether the model parameters arewithin the high PDF region (one standard deviation). Also, comparison between the observed and model data is shown for each model. This method is followed for every synthetic and field example.

\subsubsection{Model 1 (Gravity model with 10\% Random Noise)}

Inversion of the gravity data is implemented as mentioned above using noise free and noisy synthetic data. Figure 2a shows the convergence pattern for all model parameters. Figure 3a shows the histogram for all model parameters $\left(k, x_{0}, z\right.$, and $\left.q\right)$. The histogram reveals that the location of the body can be well resolved after inversion. However, there is a slight wide range in the other parameters. In the next step, since the shape factor $q$ shows near its actual value, it is set to its actual value and the inversion procedure is repeated again. Figure 4a shows that the histogram shows a definite peak at the actual value and all the parameters are well resolved. The cross-plots analysis (Figure 5a) also shows that there is a wide range in the other model parameter. After controlling $q$ to its actual value, the model parameters are very close to its actual value (Figure 5b). The fittings between the observed and model data are shown in Figure 6a. The interpreted parameters and mean model is shown in Table 1. Next, $10 \%$ Random noise is added to the data and the procedure is repeated to check the effect of noise. Figure $3 \mathrm{~b}$ shows the histogram when $q$ is uncontrolled and Figure $4 \mathrm{~b}$ shows the histogram when $q$ is controlled. Analysis of cross-plots (Figure $5 \mathrm{c}$ and $\mathrm{d}$ ) also suggests the effect of noise added in the data however, the estimated model parameters are within the uncertainty limits and within high PDF. Table 1 shows the interpreted mean model for noisy data. A fitting between the observed and model data for noisy model is shown in Figure 6b.

\subsubsection{Model 2(Gravity model with 20\% Gaussian Noise)}

Additional synthetic data for a dyke model (Table 2) and $20 \%$ Gaussian noise is also added to the synthetic data to check the effect of more noise. Inversion is implemented using noise-free and noisy synthetic data to retrieve the actual model parameters and study the effect of higher noise on the interpreted model parameters. Figure $3 \mathrm{c}$ and d shows the histogram of noise free synthetic and noisy data

\begin{tabular}{|c|c|c|c|c|c|c|}
\hline \multirow{2}{*}{$\begin{array}{l}\text { Model } \\
\text { Parameters }\end{array}$} & \multirow[t]{2}{*}{ Actual Value } & \multirow[t]{2}{*}{ Search Range } & \multicolumn{2}{|c|}{ Mean Model (Noise-free) } & \multicolumn{2}{|c|}{ Mean Model (Noisy data) } \\
\hline & & & q uncontrolled & q controlled & q uncontrolled & q controlled \\
\hline $\mathbf{k}(\mathbf{m G a l x m})$ & 1000 & $0-2000$ & $1001.6 \pm 10.1$ & $1000.3 \pm 2.3$ & $1002.9 \pm 34.4$ & $982.5 \pm 9.7$ \\
\hline $\mathbf{x}_{\mathbf{0}}(\mathbf{m})$ & 200 & $0-500$ & $200.0 \pm 0.0$ & $200.0 \pm 0.0$ & $199.9 \pm 0.2$ & $199.9 \pm 0.3$ \\
\hline $\mathbf{z}(\mathbf{m})$ & 15 & $0-30$ & $15.0 \pm 0.1$ & $15.0 \pm 0.0$ & $14.7 \pm 0.3$ & $14.6 \pm 0.3$ \\
\hline q & 0.5 & $0-2$ & $0.50 \pm 0.0$ & 0.50 (fixed) & $0.50 \pm 0.0$ & 0.50 (fixed) \\
\hline Misfit & & & $4.2 \times 10^{-8}$ & $2.6 \times 10^{-8}$ & $1.3 \times 10^{-3}$ & $1.3 \times 10^{-3}$ \\
\hline
\end{tabular}

Table 1 Actual model parameters, search range and interpreted mean model for noise free, $10 \%$ Random noise with uncertainty-Gravity data (Model 1). 
BISWAS ET AL.

\begin{tabular}{|c|c|c|c|c|c|c|}
\hline \multirow{2}{*}{$\begin{array}{l}\text { Model } \\
\text { Parameters }\end{array}$} & \multirow[t]{2}{*}{ Actual Value } & \multirow[t]{2}{*}{ Search Range } & \multicolumn{2}{|c|}{ Mean Model (Noise-free) } & \multicolumn{2}{|c|}{ Mean Model (Noisy data) } \\
\hline & & & quncontrolled & q controlled & quncontrolled & q controlled \\
\hline $\mathbf{k}(\mathbf{m G a l x m})$ & 5000 & $0-8000$ & $4986.5 \pm 96.4$ & $4996.4 \pm 12.6$ & $3740.9 \pm 162.3$ & $4765.3 \pm 37.8$ \\
\hline $\mathbf{x}_{\mathbf{0}}(\mathbf{m})$ & 250 & $0-500$ & $250.0 \pm 0.1$ & $250.0 \pm 0.0$ & $250.0 \pm 0.2$ & $250.0 \pm 0.4$ \\
\hline $\mathbf{z}(\mathbf{m})$ & 25 & $0-50$ & $24.9 \pm 0.2$ & $25.0 \pm 0.1$ & $22.2 \pm 0.4$ & $24.5 \pm 0.4$ \\
\hline$q$ & 0.5 & $0-2$ & $0.50 \pm 0.0$ & 0.50 (fixed) & $0.47 \pm 0.0$ & 0.50 (fixed) \\
\hline Misfit & & & $5.3 \times 10^{-8}$ & $2.8 \times 10^{-8}$ & $5.5 \times 10^{-3}$ & $5.5 \times 10^{-3}$ \\
\hline
\end{tabular}

Table 2. Actual model parameters, search range and interpreted mean model for noise free, 20\% Gaussian noise with uncertainty-Gravity data (Model 2).

\begin{tabular}{|c|c|c|c|c|c|c|}
\hline \multirow{2}{*}{$\begin{array}{l}\text { Model } \\
\text { Parameters }\end{array}$} & \multirow[t]{2}{*}{ Actual Value } & \multirow[t]{2}{*}{ Search Range } & \multicolumn{2}{|c|}{ Mean Model (Noise-free) } & \multicolumn{2}{|c|}{ Mean Model (Noisy data) } \\
\hline & & & quncontrolled & q controlled & quncontrolled & q controlled \\
\hline$k(n T)$ & 800 & $0-1000$ & $786.4 \pm 29.4$ & $800.0 \pm 3.6$ & $964.0 \pm 56.8$ & $795.5 \pm 16.6$ \\
\hline $\mathbf{x}_{0}(\mathbf{m})$ & 200 & $0-500$ & $200.0 \pm 0.0$ & $200.0 \pm 0.0$ & $199.9 \pm 0.2$ & $199.9 \pm 0.2$ \\
\hline $\mathbf{z}(\mathbf{m})$ & 10 & $0-20$ & $9.9 \pm 0.1$ & $10.0 \pm 0.0$ & $10.3 \pm 0.2$ & $9.9 \pm 0.2$ \\
\hline$q$ & 1.0 & $0-2$ & $1.0 \pm 0.0$ & 1.0 (fixed) & $1.0 \pm 0.0$ & $1.0($ fixed) \\
\hline Misfit & & & $4.1 \times 10^{-8}$ & $3.9 \times 10^{-10}$ & $1.7 \times 10^{-4}$ & $1.6 \times 10^{-4}$ \\
\hline
\end{tabular}

Table 3. Actual model parameters, search range and interpreted mean model for noise free, $10 \%$ Random noise with uncertainty-Magnetic data (Model 3).

\begin{tabular}{|c|c|c|c|c|c|c|}
\hline \multirow{2}{*}{$\begin{array}{l}\text { Model } \\
\text { Parameters }\end{array}$} & \multirow[t]{2}{*}{ Actual Value } & \multirow[t]{2}{*}{ Search Range } & \multicolumn{2}{|c|}{ Mean Model (Noise-free) } & \multicolumn{2}{|c|}{ Mean Model (Noisy data) } \\
\hline & & & quncontrolled & q controlled & quncontrolled & q controlled \\
\hline $\mathbf{k}(\mathbf{n T})$ & 400 & $0-800$ & $409.5 \pm 30.6$ & $399.9 \pm 1.4$ & $635.26 \pm 60.2$ & $385.1 \pm 7.1$ \\
\hline $\mathbf{x}_{0}(\mathbf{m})$ & 250 & $0-500$ & $250.0 \pm 0.1$ & $250.0 \pm 0.0$ & $250.1 \pm 0.2$ & $250.1 \pm 0.3$ \\
\hline $\mathbf{z}(\mathbf{m})$ & 30 & $0-50$ & $30.1 \pm 0.3$ & $30.0 \pm 0.1$ & $31.4 \pm 0.4$ & $29.5 \pm 0.4$ \\
\hline q & 0.5 & $0-2$ & $1.0 \pm 0.0$ & 1.0 (fixed) & $1.1 \pm 0.0$ & 1.0 (fixed) \\
\hline Misfit & & & $4.7 \times 10^{-7}$ & $1.3 \times 10^{-8}$ & $3.6 \times 10^{-3}$ & $3.6 \times 10^{-3}$ \\
\hline
\end{tabular}

Table4. Actual model parameters, search range and interpreted mean model for noise free, $20 \%$ Gaussian noise with uncertainty-Magnetic data (Model 4).

when $q$ is uncontrolled. Figure $4 \mathrm{c}$ and $\mathrm{d}$ shows the histogram of noise free synthetic and noisy data when $q$ is controlled. Cross-plots also suggest the same as shown in Model 1 and for brevity, it is not presented here. Fittings between the observed and model response for this noise free and noisy model is shown in Figure $6 \mathrm{c}$ and $\mathrm{d}$.

\subsubsection{Model 1 (Magnetic model with 10\% Random Noise)}

Inversion of the magnetic data is executed as mentioned above using noise free and noisy synthetic data. Figure $2 \mathrm{~b}$ shows the convergence pattern for all model parameters. Figure 7a shows the histogram for all model parameters $\left(k, x_{0}, z\right.$, and $\left.q\right)$. The histogram reveals that the location of the body can be well resolved after VFSA inversion. However, there is a slight wide range in the other parameters such as $k$. Hence, in the following step, the shape factor $q$ is controlled to its actual value and the inversion procedure is repeated again. Figure $8 \mathrm{a}$ shows that the histogram shows a definite peak at the actual value and all the parameters are well resolved. The cross-plots analysis (Figure 9a) also shows that there is a wide range in the other model parameter. After constraining $q$ the model parameters are very close to its actual value (Figure $9 \mathrm{~b}$ ). The fittings between the observed and model data are shown in Figure 10a. The interpreted parameters and mean model is shown in Table 1 . Next, $10 \%$ Random noise is added to the data and the procedure is repeated to check the effect of noise in magnetic data as well. Figure $7 \mathrm{~b}$ shows the histogram when $q$ is free and Figure $8 \mathrm{~b}$ shows the histogram when $q$ is controlled. Cross-plots also suggest the same as shown in Model 1 (gravity data) and for brevity, it is not presented here, and however, it is also within the uncertainty 

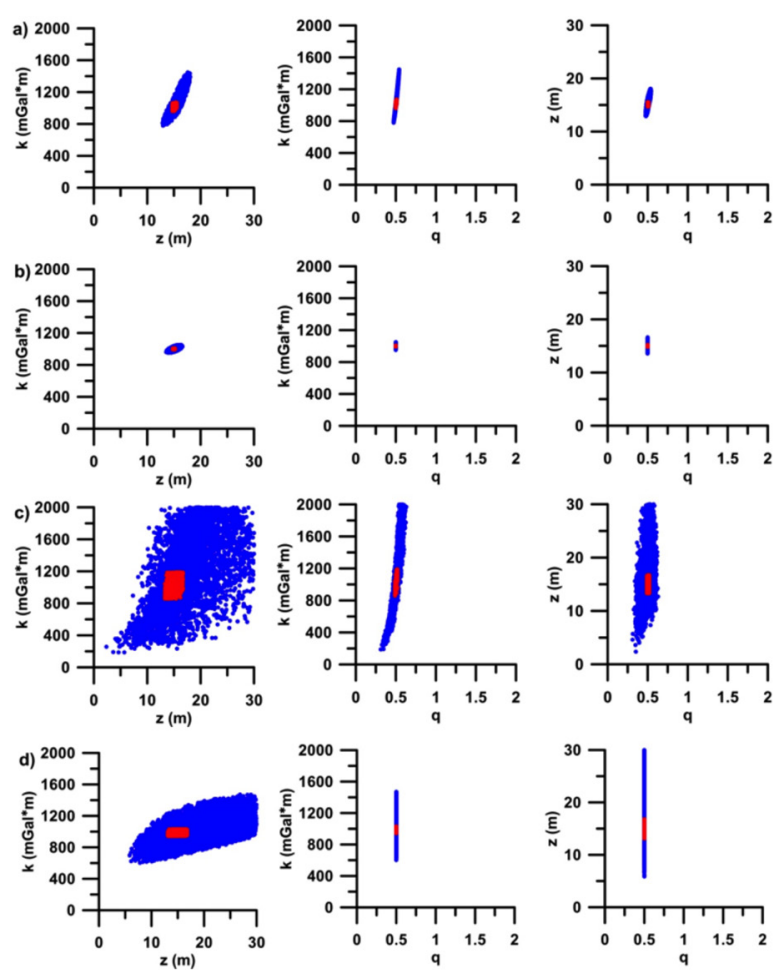

Figure 5. Gravity Data: (a) Scatter-plots between amplitude coefficient $(k)$, depth (z), shape factor (q) for all models having misfit $<$ threshold $\left(10^{-4}\right.$ for noise-free data) (blue), and models with PDF $>60.65 \%$ (red) for noise free data when $q$ is uncontrolled; (b) Scatter-plots between amplitude coefficient $(k)$, depth $(z)$, shape factor $(q)$ for all models having misfit $<$ threshold ( $10^{-4}$ for noise-free data) (blue), and models with PDF $>60.65 \%$ (red) for noise free data when $q$ is controlled; (c) Scatter-plots between amplitude coefficient $(k)$, depth $(\mathrm{z})$, shape factor $(q)$ for all models having misfit $<$ threshold $\left(10^{-2}\right.$ for noisy data) (blue), and models with PDF $>60.65 \%$ (red) for noisy data when $q$ is uncontrolled; (d) Scatter-plots between amplitude coefficient $(k)$, depth $(z)$, shape factor (q) for all models having misfit $<$ threshold ( $10^{-2}$ for noisy data) (blue), and models with PDF $>60.65 \%$ (red) for noisy data when $q$ is controlled.
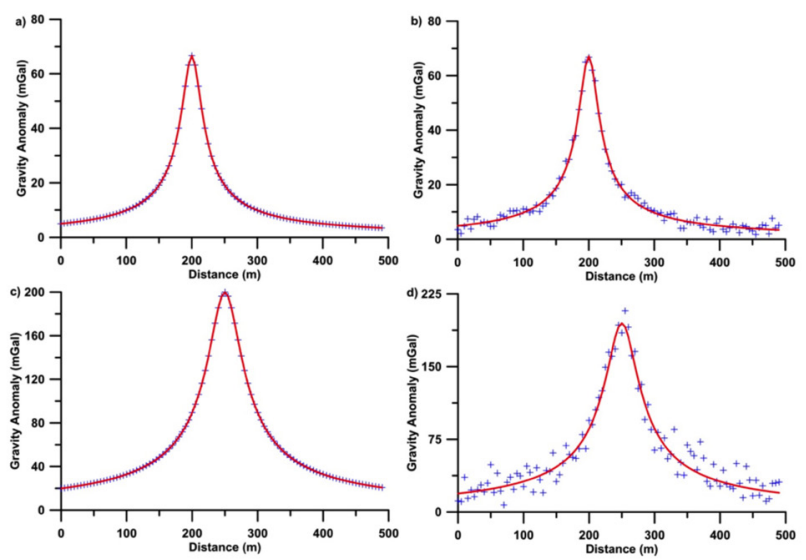

Figure 6. Gravity Data: Fittings between the observed and model data for Thin dyke: Model 1- (a) noise-free synthetic data and (b) 10\% Random noisy synthetic data, and Model 2- (c) noise-free synthetic data and (d) $20 \%$ Gaussian noisy synthetic data.

limits and within high PDF. Table 3 shows the interpreted mean model for noisy data. A fitting betwe-

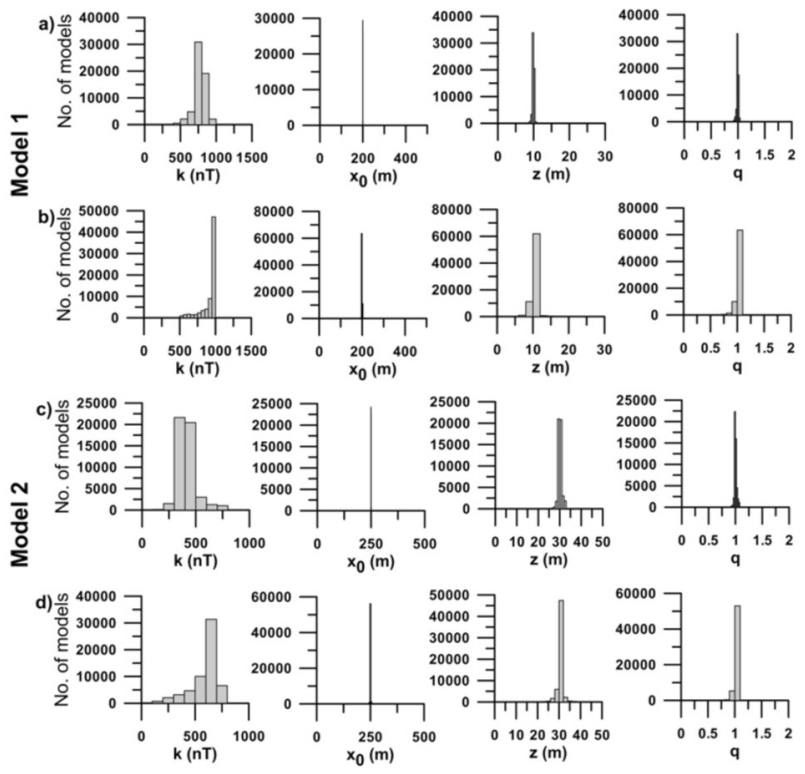

Figure 7. Magnetic Data: (a) Histograms of all accepted models having misfit $<10^{-4}$ for noise-free synthetic data when $q$ is uncontrolled (b) Histograms of all accepted models having misfit $<10^{-2}$ for noisy synthetic data ( $10 \%$ Random) when $q$ free for thin dyke-Model 1, (c)Histograms of all accepted models having misfit $<10^{-4}$ for noise-free synthetic data when $q$ is uncontrolled (b) Histograms of all accepted models having misfit $<10^{-2}$ for noisy synthetic data ( $20 \%$ Gaussian) when $q$ is uncontrolled for thin dyke-Model 2.

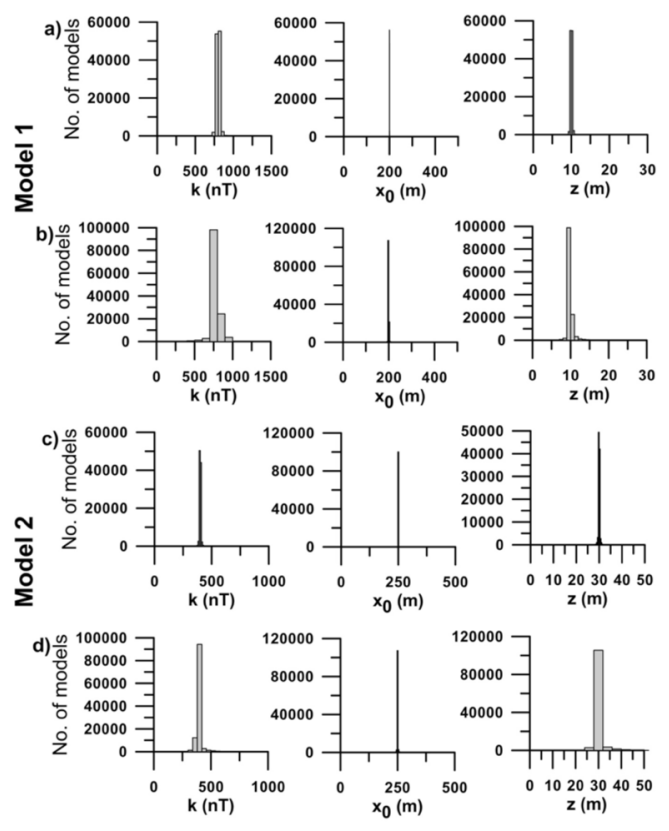

Figure 8. Magnetic Data: (a) Histograms of all accepted models having misfit $<10^{-4}$ for noise-free synthetic data when $q$ is controlled (b) Histograms of all accepted models having misfit $<10^{-2}$ for noisy synthetic data ( $10 \%$ Random) when $q$ fixed for thin dyke-Model 1, (c) Histograms of all accepted models having misfit $<10^{-4}$ for noise-free synthetic data when $q$ fixed (b) Histograms of all accepted models having misfit $<10^{-2}$ for noisy synthetic data ( $20 \%$ Gaussian) when $q$ is controlled for thin dyke-Model 2 .

en the observed and model data for noisy model is shown in Figure 10b. 

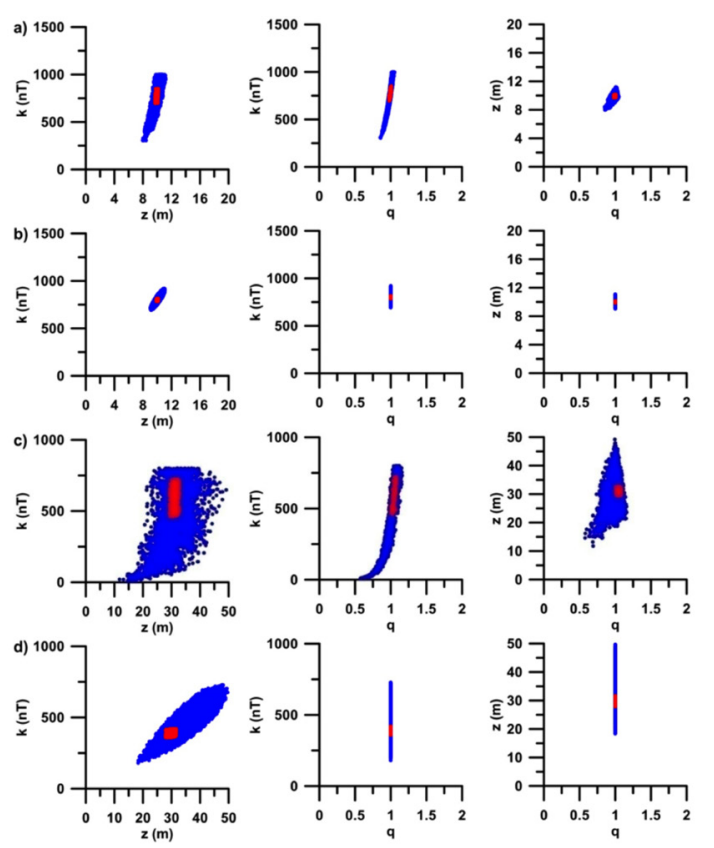

Figure 9. Gravity Data: (a) Scatter-plots between amplitude coefficient (k), depth ( $\mathrm{z}$ ), shape factor (q) for all models having misfi$\mathrm{t}<$ threshold $\left(10^{-4}\right.$ for noise-free data) (blue), and models with PDF $>60.65 \%$ (red) for noise free data when $q$ is uncontrolled; (b) Scatter-plots between amplitude coefficient $(\mathrm{k})$, depth ( $\mathrm{z}$ ), shape factor (q) for all models having misfit $<$ threshold $\left(10^{-4}\right.$ for noise-free data) (blue), and models with PDF $>60.65 \%$ (red) for noise free data when $q$ is controlled; (c) Scatter-plots between amplitude coefficient (k), depth $(z)$, shape factor $(q)$ for all models having misfit $<$ threshold ( $10^{-2}$ for noisy data) (blue), and models with PDF $>60.65 \%$ (red) for noisy data when $q$ is uncontrolled; (d) Scatter-plots between amplitude coefficient $(\mathrm{k})$, depth $(\mathrm{z})$, shape factor $(q)$ for all models having misfit $<$ threshold ( $10^{-2}$ for noisy data) (blue), and models with PDF $>60.65 \%$ (red) for noisy data when $q$ is controlled.
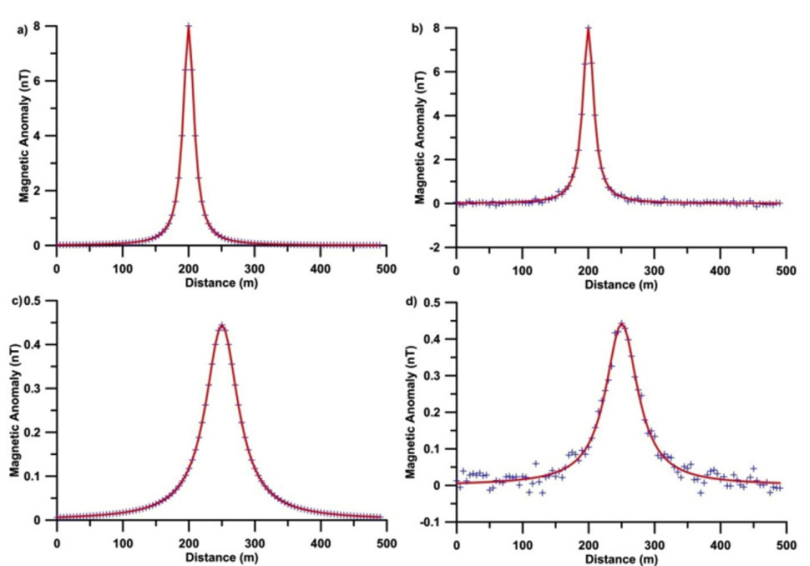

Figure 10. Magnetic Data: Fittings between the observed and model data for Thin dyke: Model 1- (a) noise-free synthetic data and (b) $10 \%$ Random noisy synthetic data, and Model 2- (c) noise-free synthetic data and (d) $20 \%$ Gaussian noisy synthetic data.

\subsubsection{Model 2 (Magnetic model with 20\% Gaussian} Noise)

Another synthetic data for a dyke model (Table 4) and $20 \%$ Gaussian noise is also added to the syn- thetic data to check the effect of more noise. Inversion is implemented using noise-free and noisy synthetic data to retrieve the actual model parameters and study the effect of higher noise on the interpreted model parameters. Figure $7 \mathrm{c}$ and d shows the histogram of noise free synthetic and noisy data when $q$ is uncontrolled. Figure $8 \mathrm{c}$ and d shows the histogram of noise free synthetic and noisy data when $q$ is controlled. Cross-plots also suggest the same as shown in Model 1 and are shown in Figure 9c and $d$ to check the effect of higher amount of noise in the data. The estimated model parameters for $20 \%$ Gaussian noisy data also reveals that the interpreted parameters are within the estimated uncertainty limits and high PDF. Fittings between the observed and model response for this noise free and noisy model is shown in Figure 10c and d.

\subsection{Field Example}

To show the efficacy of the approach three field examples of gravity and magnetic anomaly were presented. It is worth to make a note that the field data is often corrupted with noise and in common, exact shape of the subsurface structure cannot be found in geological nature. Hence, field data cannot be fitted accurately well with the model response from the dyke like structure.

Moreover, it is important to note that in nature, real structures might not have the standard geometrical shape and structure. Along these lines, modeling and inversion of real field information utilizing the specified standard geometrical definition may not yield the genuine subsurface structure. Any, deviation of the real structure from the displayed structure can be comprehended as systematic erraticism from the demonstrated curves brought on by the distinction from dyke like structures.

Under such conditions, the multi-dimensional objective function will be to a great degree of unpredictable and straightforward inversion methodology may neglect to show the subsurface structure. Henceforth, global optimization is much more important to manage such conditions.

Besides, it ought to be highlighted that unpredictable modeled bodies can't be resolved correctly utilizing any interpretation strategy unless and until numerous bore-hole data are accessible. Hence, the primary objectives is to find out the near probable shape, depth at where the body is located and the exact location of the body from the surface, which can be successfully utilized for drilling purposes. 

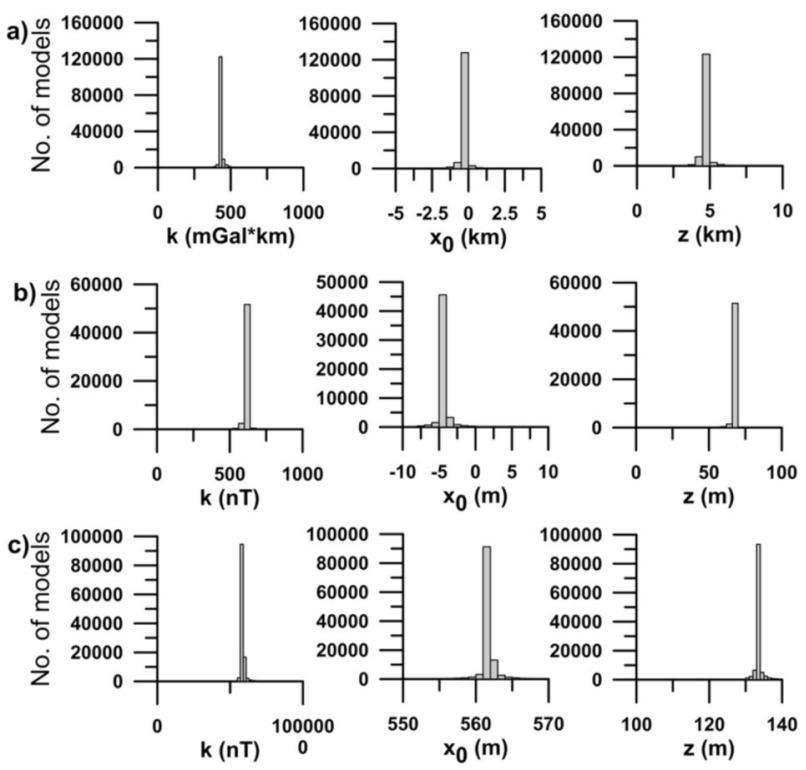

Figure 11. (a) Histograms of all accepted models having misfit $<10^{-2}$ for field data when $q$ fixed for gravity anomaly, (b) Histograms of all accepted models having misfit $<10^{-2}$ for field data when $q$ is controlled for magnetic anomaly, (c) Histograms of all accepted models having misfit $<10^{-2}$ for field data when $q$ is controlled for aeromagnetic anomaly.

3.2.1 Leona Anomaly, South Saint-Louis, Western Coastline, Senegal

A residual gravity anomaly over an area $(30 \mathrm{~km}$ length) on the west coast of Senegal in West Africa [Nettleton, 1976] is shown in Figure 13. This anomaly was interpreted by several authors as spherical structure [Tlas et al. 2005, Asfahani and Tlas 2012, Mehanee 2014].

VFSA optimization is repeated for this profile as mentioned for synthetic data.

Table 5 depicts the interpreted model parameters and comparison with other published results. Histogram shows that the model parameters are well resolved when $q$ is controlled (Figure 11a) and cross plots also suggest that the estimated parameters are within the uncertainty limits (Figure 12a) and high PDF. The depth of the body estimated in the present study is $4.6 \mathrm{~km}$.

The depth obtained by Tlas et al. $2005(z=9.17$ $\mathrm{km})$, Asfahani and Tlas, $2012(\mathrm{z}=9.13 \mathrm{~km})$, Mehanee, $2014(z=12.2 \mathrm{~km})$ are presented as interpreted as sphere. Moreover, Mehanee, 2014 and Biswas, 2015 also interpreted the same anomaly as vertical cylinder as well where the depth is estimated at 4.59 and $4.6 \mathrm{~km}$ respectively. In the present study, it is found that the shape factor is pointing towards a thin dyke and interpreted the same. Comparison of interpretation results by various methods also reveal that present approach is
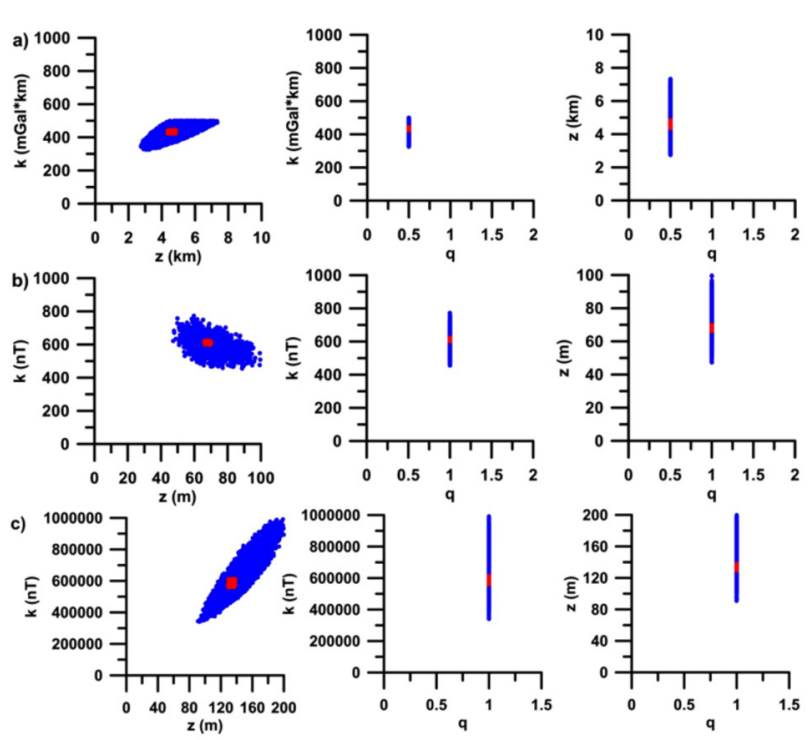

Figure 12. (a) Scatter-plots between amplitude coefficient (k), depth $(\mathrm{z})$, shape factor $(q)$ for all models having misfit $<$ threshold $\left(10^{-2}\right.$ for field data) (blue), and models with PDF $>60.65 \%$ (red) for field data when $q$ is controlled for gravity data; (b) Scatter-plots between amplitude coefficient $(\mathrm{k})$, depth $(\mathrm{z})$, shape factor $(q)$ for all models having misfit $<$ threshold $\left(10^{-2}\right.$ for field data) (blue), and models with PDF $>60.65 \%$ (red) for field data when $q$ is controlled for magnetic data, (c) Scatter-plots between amplitude coefficient $(\mathrm{k})$, depth $(\mathrm{z})$, shape factor $(q)$ for all models having misfit $<$ threshold ( $10^{-2}$ for field data) (blue), and models with PDF $>60.65 \%$ (red) for field data when $q$ is controlled for aeromagnetic data.

in good agreement with other interpretation methods. A comparison between the field data and modeled data is shown in Figure 13.

\subsubsection{Pima Copper deposit, Arizona, USA}

A 750 m-long magnetic anomaly profile caused due to a thin dike over the Pima Copper mine, Arizona, United States (Gay 1963) is taken (Figure 14). This anomaly was interpreted by several authors (Tlas and Asfahani, 2015, Abdelrahman and Essa, 2015, Asfahani and Tlas, 2007, Asfahani and Tlas, 2004, Abdelrahman and Sharafeldin, 1996, Gay, 1963) assuming a thin dyke model. The anomaly is interpreted using VFSA to obtain the different parameters. The VFSA process is applied in this magnetic field anomaly keeping $q$ free and fixed as discussed in synthetic model data.

The histogram shows that all the model parameters are well determined when $q$ is controlled (Figure $11 \mathrm{~b})$ and cross-plots also advocate that the estimated parameters are within the uncertainty limits (Figure 12b) with high PDF. The interpreted results are shown in Table 6 . The depth of the body estimated in the present study is $68 \mathrm{~m}$.

The depth obtained by other workers such as Gay, $1963(z=70 \mathrm{~m})$, Abdelrahman and Sharafeldin, 1996 
$(z=66 \mathrm{~m})$, Asfahani and Tlas, $2004(z=71.50 \mathrm{~m})$, Asfahani and Tlas, $2007(\mathrm{z}=71.50 \mathrm{~m})$, Abdelrahman and Essa, $2015(z=60 \mathrm{~m})$, Tlas and Asfahani, 2015 $(\mathrm{z}=64.1 \mathrm{~m})$, Ekinci, $2016(\mathrm{z}=67.9 \mathrm{~m}$ using derivative method and $68.3 \mathrm{~m}$ using PSO) and Abo-Ezz and Essa, $2016(z=61.5 \mathrm{~m})$ are in good agreement with the other published literatures as shown in Table 6. Figure 14 depicts the fitting between the observed and interpreted mean model.

The other results are also in respectable agreement.

\subsubsection{Matheson area, Northern Ontario, Canada}

Another field example is taken from the total field aeromagnetic anomaly (Srivastava and Agarwal, 2010) over a magnetic body associated with a mapped bedrock diabase dyke in the Matheson area of northern Ontario, Canada (Figure 15). The amplitude of 2-D analytic signal, from the measured magnetic field anomaly for the same example is taken from Srivastava and Agarwal, 2010. The aeromagnetic data was taken over a flight height of $12 \mathrm{~m}$ (Salem et al. 2005). The anomaly is interpreted using the same approach as discussed earlier. The histogram and cross-plots are shown in Figure 11c and 12c. The interpreted results are shown in Table 7. The depth of the body estimated in the present study is 133.4 $\mathrm{m}$. The depth obtained by Srivastava and Agarwal, 2010 $(z=135.2 \mathrm{~m})$, Vallee et al., $2004(z=145)$, Salem et al., $2005(\mathrm{z}=139.6 \mathrm{~m})$ and Agarwal and Srivastava, $2008(\mathrm{z}=$ $142.6 \mathrm{~m}$ ) are in good agreement. Figure 14 depicts the fitting between the measured amplitude of 2-D analytical signal and model amplitude. A borehole taken at that location intersects the bedrock at $41 \mathrm{~m}$ (Vallee et al. 2004).

\section{Conclusions}

In the present work, an attempt is being made to test the applicability and effectiveness of VFSA on the parameter estimations from potential field anomalies using total gradient method. As far as this work is concerned, this is the first attempt of applying VFSA for model parameter estimations using total gradient of gravity and magnetic anomaly. In the present algorithm, the test studies are performed using theoretically produced data and field data sets. The determination of the appropriate amplitude coefficient, location, depth and shape, of a buried structure from total gradient anomaly profile can be well resolved using the present method. Synthetic data experiments are performed using both noise-free and noisy gravity data sets due to simple-shaped causative bodies. The present study reveals, while optimizing all model parameters (amplitude

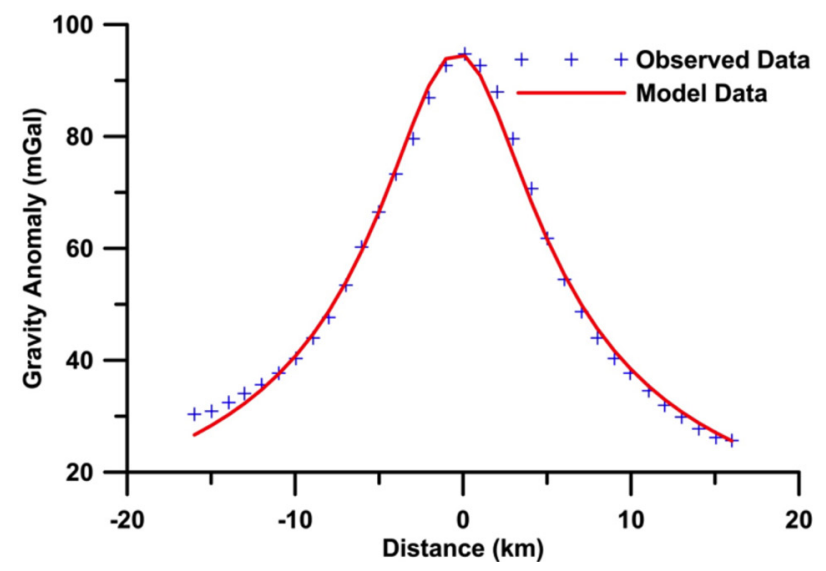

Figure 13. Fittings between the observed and model data for Leona Anomaly, South Saint-Louis, Western Coastline, Senegal.

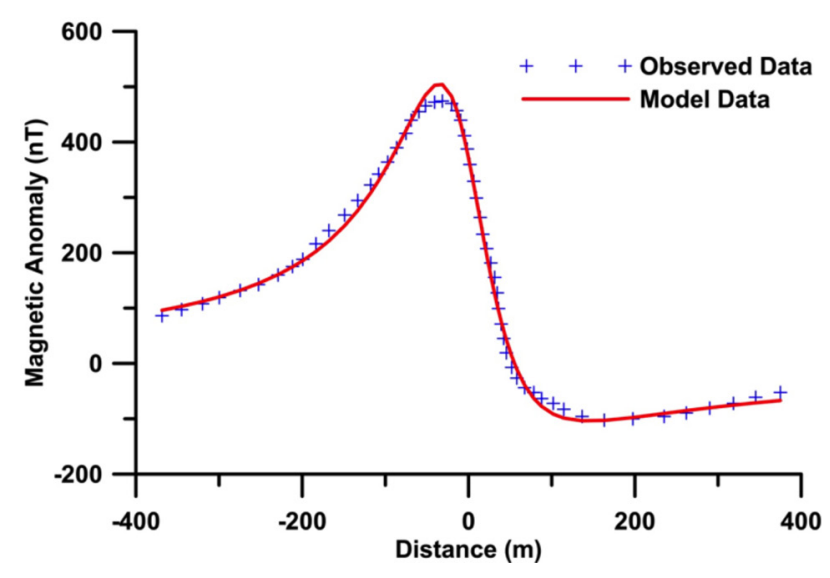

Figure 14. Fittings between the observed and model data for Pima copper deposit, Arizona, USA.

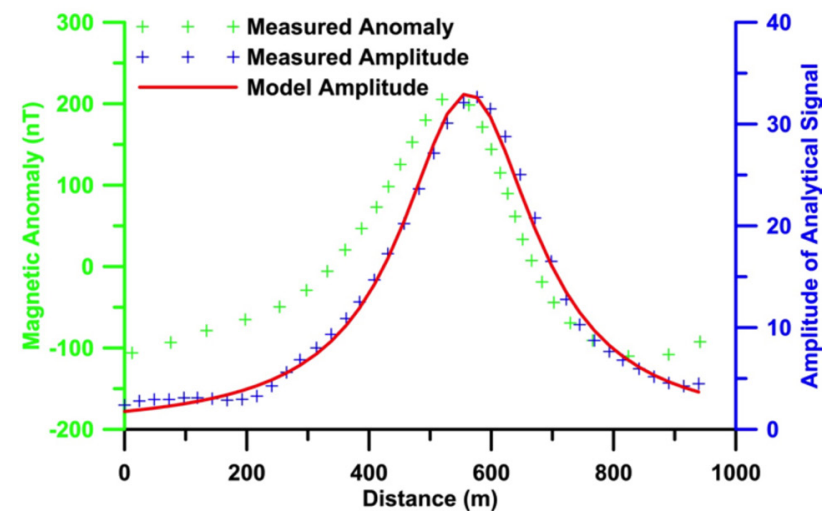

Figure 15. Fittings between the measured amplitude of $2 \mathrm{D}$ analytical signal and model amplitude for Matheson area, Northern Ontario, Canada.

coefficient, location, depth, shape) together, the VFSA method yields very good results. The resulting histogram and cross-plots analysis suggests that 


\begin{tabular}{|c|c|c|c|c|c|c|c|}
\hline $\begin{array}{l}\text { Model } \\
\text { Parameters }\end{array}$ & $\begin{array}{l}\text { Search } \\
\text { Range }\end{array}$ & $\begin{array}{l}\text { Present method } \\
\text { (VFSA) Thin Dyke }\end{array}$ & Tlas et al. [2012] & $\begin{array}{c}\text { Ashfahani and } \\
\text { Tlas }[2012]\end{array}$ & $\begin{array}{c}\text { Mehanee [2014] } \\
\text { (Sphere) }\end{array}$ & $\begin{array}{l}\text { Mehanee [2014] } \\
\text { (Vertical Cylinder) }\end{array}$ & $\begin{array}{l}\text { Biswas [2015] } \\
\text { (Vertical Cylinder) }\end{array}$ \\
\hline $\mathbf{k}(\mathbf{m G a l x k m})$ & $10-1000$ & $433.6 \pm 2.94$ & $\begin{array}{c}6971.83 \\
\mathrm{mGalxkm}^{2}\end{array}$ & $\begin{array}{c}6931.78 \\
\text { mGalxkm }^{2}\end{array}$ & $\begin{array}{l}13026.03 \\
\mathrm{mGalxkm}^{2}\end{array}$ & 436.31 & $94.7 \pm 0.7$ \\
\hline$x_{0}(k m)$ & $-5-5$ & $-0.4 \pm 0.0$ & 0.22 & - & - & - & $-0.4 \pm 0.0$ \\
\hline $\mathbf{z}(\mathbf{k m})$ & $0-20$ & $4.6 \pm 0.0$ & 9.17 & 9.13 & 12.2 & 4.59 & $4.6 \pm 0.0$ \\
\hline$q$ & 0.5 & 0.5 & 1.499 & 1.499 & 1.5 & 0.5 & 0.5 \\
\hline Misfit & & $3.8 \times 10^{-4}$ & - & - & - & - & $3.8 \times 10^{-4}$ \\
\hline
\end{tabular}

Table 5. Search range and interpreted mean model for Leona Anomaly, South Saint-Louis, Western Coastline, Senegal.

\begin{tabular}{|c|c|c|c|c|c|c|c|c|c|c|}
\hline $\begin{array}{l}\text { Model } \\
\text { Parame- } \\
\text { ters }\end{array}$ & $\begin{array}{l}\text { Search } \\
\text { Range }\end{array}$ & $\begin{array}{l}\text { Present } \\
\text { method } \\
\text { (VFSA) } \\
\text { Thin Dyke }\end{array}$ & $\begin{array}{c}\text { Abo-Ezz } \\
\text { and Essa } \\
{[2016]}\end{array}$ & $\begin{array}{c}\text { Ekinci } \\
{[2016]} \\
\text { PSO }\end{array}$ & $\begin{array}{c}\text { Tlas and } \\
\text { Asfahani } \\
{[2015]}\end{array}$ & $\begin{array}{c}\text { Abdel- } \\
\text { rahman } \\
\text { and Essa } \\
{[2015]}\end{array}$ & $\begin{array}{c}\text { Asfahani } \\
\text { and Tlas } \\
{[2007]}\end{array}$ & $\begin{array}{c}\text { Asfahani } \\
\text { and Tlas } \\
{[2004]}\end{array}$ & $\begin{array}{l}\text { Abdelrah- } \\
\text { man and } \\
\text { Sharafel- } \\
\text { din [1996] }\end{array}$ & $\begin{array}{c}\text { Gay } \\
{[1963]}\end{array}$ \\
\hline $\mathbf{k}(\mathbf{n} T)$ & $0-1000$ & $613.0 \pm 2.2$ & 1219 & 39267.31 & 42700 & - & 577.6 & 577.61 & 596.5 & - \\
\hline $\mathbf{x}_{0}(\mathrm{~km})$ & $-50-50$ & $-4.3 \pm 0.2$ & - & - & - & - & - & - & - & - \\
\hline $\mathrm{z}(\mathrm{km})$ & $0-100$ & $68.0 \pm 1.7$ & 61.5 & 68.29 & 64.1 & 60 & 71.50 & 71.50 & 66 & 70 \\
\hline$\theta\left({ }^{\circ}\right)$ & $-90-90$ & - & -66.4 & -50.76 & -44.7 & - & -50.50 & -50.46 & -53 & -50 \\
\hline$q$ & 1.0 & 1.0 & - & - & 1.0 & 0.95 & - & - & - & - \\
\hline Misfit & & $8.3 \times 10^{-4}$ & - & - & - & - & - & - & - & - \\
\hline
\end{tabular}

Table 6. Search range and interpreted mean model for Pima Copper deposit, Arizona, USA.

\begin{tabular}{|c|c|c|c|c|c|c|}
\hline $\begin{array}{l}\text { Model } \\
\text { Parameters }\end{array}$ & Search Range & $\begin{array}{c}\text { Present method } \\
\text { (VFSA) }\end{array}$ & $\begin{array}{l}\text { Srivastava and } \\
\text { Agrawal, } 2010\end{array}$ & $\begin{array}{c}\text { Agrawal and } \\
\text { Srivastava, } 2008\end{array}$ & $\begin{array}{c}\text { Salem et al., } \\
2005\end{array}$ & $\begin{array}{c}\text { Vallee et al., } \\
2004\end{array}$ \\
\hline $\mathbf{k}(\mathbf{n} \mathbf{T})$ & $100-10^{6}$ & $586830.2 \pm 6333.87$ & 4286 & - & - & - \\
\hline $\mathbf{x}_{0}(\mathrm{~km})$ & $400-700$ & $561.9 \pm 0.7$ & 563.6 & 567 & 752.2 & - \\
\hline $\mathbf{z}(\mathbf{m})$ & $0-200$ & $133.4 \pm 0.9$ & 135.2 & 142.6 & 139.6 & 145 \\
\hline$q$ & 1.0 & 1.0 & 1.0 & 1.16 & 1.13 & 1.2 \\
\hline Misfit & & $8.1 \times 10^{-4}$ & - & - & - & - \\
\hline
\end{tabular}

Table 7. Search range and interpreted mean model for Matheson area, Northern Ontario, Canada.

the obtained parameters are within the high probability areas. The efficacy of this approach has been successfully proved, established and validated using noise-free and noisy synthetic data. The applicability of this method for practical application in mineral exploration is effectively illustrated on three field examples. The method can also be used to interpret multiple structures from the anomaly data. The estimated inverse parameters for the field data are found to be in excellent agreement with the other methods as well as from the geological results.

Acknowledgements. We thank the editor Prof. Paola De Michelis and an anonymous reviewer whose comments and suggestion has improved the quality of the manuscript. The authors would like to thank Prof. A. K. Gupta, Director, Wadia Institute of Himalayan Geology for necessary facilities to complete this work.

\section{Appendix I}

We present here the detail explanation of TG. It is well known what is currently normally called the $3 \mathrm{D}$ analytical signal (and same for 2D case additionally) ought to accurately be known as the total gradient. It might be called attention to here that the analytical signal in 3D for total magnetic anomaly does not comply with the state of being analytic unless the anomaly is reduced to pole [Haney et al. 2003]. All in all, TG has been approximated by a bell-shaped function [Nabighian 1972, Green 1976, Stanley and Green 1976, Srivastava and Agarwal 2009, 2010, Srivastava et al. 2014] for $2 \mathrm{D}$ source geometries (or profile information) and it is additionally valid for $2 \mathrm{D}$ circularly symmetrical anomalies (in perception plane) created by 3D circularly symmetrical sources, to be specific, a sphere or a vertical cylinder delivering different potential field. More- 
over, the total magnetic field anomaly (in 2D) must be reduced to pole (RTP) before TG examination [Haney et al. 2003]. The anomaly constriction rate [Ravat 1996] or decay rate ( $\beta$ ) - see Appendix II) of TG is represented by a power law which is identified with source geometry. The analytical signal, albeit broadly utilized as a part of magnetic, is utilized little as a part of gravity systems, fundamentally due to the sparser way of gravity information, which makes the count of subordinates less dependable. For magnetic profile information the level and vertical derivatives fit actually into the genuine and nonexistent parts of analytic signals [Nabighian 1972]. In two dimensions [Nabighian 1972], the amplitude of the analytical signal is the same as the TG. In three dimensions, Roest et al. [1992] presented the TG of magnetic anomaly data as an augmentation to the $2 \mathrm{D}$ case.

The outcomes acquired for magnetic anomaly data can be reached out to gravity information too. Assist, the surmised horizontal area of the causative source corresponds to the pinnacle of TG. Amplitude of the 2-D analytic signal of the magnetic anomaly profile is autonomous of the bearings of the Earth's magnetic field vector and leftover polarization of the causative source. It shows crests relating to the areas of the sides of a causative source, demonstrated by say a polygon. It likewise shows a pinnacle comparing to various source geometries identified with the structural indices. This amplitude is figured from the first order horizontal and vertical derivatives of the field magnetic anomaly and is moderately less eccentricity than second order derivatives.

\section{Appendix II}

We show the detailed derivation of the TG. Following Srivastava et al. [2014], Let us assume that $D(x)$ correspond to the potential field function satisfying the Laplace's equation in 2-D. This means that a profile perpendicular to the strike length of the contributing source from any structure. The first order horizontal $(x)$ and vertical $(z)$ derivatives, computed via the wave number domain computation or any other appropriate method is represented as

$$
\left(\frac{\delta D}{\delta x}\right) \text { and }\left(\frac{\delta D}{\delta z}\right) \text { respectively. }
$$

The amplitude of the total gradient, $D(x)$ is defined by

$$
|A(x)|=\sqrt{\left(\left(\frac{\delta D}{\delta x}\right)^{2}+\left(\frac{\delta D}{\delta z}\right)^{2}\right)}
$$

The total gradient (TG) field over several idealized source geometries can be approximated by

$$
A(x)=\frac{B}{r^{\beta}}
$$

where

$$
r^{2}=\left|\left(x-x_{0}\right)^{2}+z^{2}\right|
$$

$x_{0}$ and $z_{0}$ are the horizontal location and depth of causative source, $\beta$ - a positive integer called 'source geometry factor' (SGF), and $B$ is a constant governing the amplitude of TG.

The first order horizontal and vertical derivatives of the magnetic anomaly over a corner formed by two infinite extending edges of a horizontal faulted slab are related through Hilbert transform pair as shown by Nabighian [1972]. The concept of analytic signal (AS) in complex domain is written as

$$
A(x)=\frac{d D}{d x}-i \frac{d D}{d z}
$$

where and its amplitude is given by equation (2) and can be approximated by a generalized equation as

$$
V(x)=k\left[\frac{1}{\left[\left(x-x_{0}\right)^{2}+(z)^{2}\right]^{q}}\right]
$$

where $K$ is the amplitude factor related to the physical properties of the source and $q$ is the shape factor $[\mathrm{Ab}$ delrahman et al. 2001, Srivastava et al. 2014].

\section{References}

Abdelrahman, E. M., Essa, K. S., (2015). A New Method for Depth and Shape Determinations from Magnetic Data. Pure and Applied Geophysics, 172(2), 439-460.

Abdelrahman, E. M., Abo-Ezz, E. R., Essa, K. S., (2012). Parametric inversion of residual magnetic anomalies due to simple geometric bodies. Exploration Geophysics, 43, 178-189.

Abdelrahman, E. M., Soliman, K. S., El-Araby, T. M., Abo-Ezz, E. R., and Essa, K. S., (2009). A least-squares standard deviation method to interpret magnetic anomalies due to thin dikes. Near Surface Geophysics, 7, 41-46.

Abdelrahman, E. M., Abo-Ezz, E. R., Essa, K. S., EL-Araby, T. M., Soliman, K. S., (2007). A new least-squares minimization approach to depth and shape determination from magnetic data. Geophysical Prospecting, 55, 433-446.

Abdelrahman, E. M., Abo-Ezz, E. R., Essa, K.. S., El-Araby, T. M., and Soliman, K. S., (2006). A least-squares variance analysis method for shape and depth 
estimation from gravity data. Journal of Geophysics and Engineering, 3, 143-153.

Abdelrahman, E. M., and Essa, K. S., (2005). Magnetic interpretation using a least-squares, depth-shape curves method. Geophysics, 70, L23-L30.

Abdelrahman, E. M., El-Araby, T. M., and Essa, K. S., (2003). A least-squares minimisation approach to depth, index parameter, and amplitude coefficient determination from magnetic anomalies due to thin dykes. Exploration Geophysics, 34, 241-248.

Abdelrahman, E. M., El-Araby, T. M. El-Araby, H. M. and Abo-Ezz, E. R., (2001a). Three Least squares Minimization Approaches to Depth, Shape, and Amplitude Coefficient Determination from Gravity Data. Geophysics, 66, 1105-1109.

Abdelrahman, E. M., El-Araby, T. M. El-Araby, H. M. and Abo-Ezz, E. R., (2001b). A New Method for Shape and Depth Determinations from Gravity Data. Geophysics, 66, 1774-1780.

Abdelrahman, E. M., Sharafeldin, S. M., (1996). An iterative least-squares approach to depth determination from residual magnetic anomalies due to thin dikes. Applied Geophysics, 34, 213-220.

Abdelrahman, E. M. and Sharafeldin, S. M., (1995a). A Least-squares Minimization Approach to Depth Determination from Numerical Horizontal Gravity Gradients. Geophysics, 60, 1259-1260.

Abdelrahman, E. M. and Sharafeldin, S. M., (1995b). A Least-squares Minimization Approach to Shape Determination from Gravity Data. Geophysics, 60, 589-590.

Abdelrahman, E. M., (1994). A rapid approach to depth determination from magnetic anomalies due to simple geometrical bodies. Journal of University of Kuwait Science, 21, 109-115.

Abdelrahman, E. M. and El-Araby, T. M., (1993). A Least-squares Minimization Approach to Depth Determination from Moving Average Residual Gravity Anomalies. Geophysics, 59, 1779-1784.

Abdelrahman, E. M., Bayoumi, A. I., and El-Araby, H. M., (1991). A Least-squares Minimization Approach to Invert Gravity Data. Geophysics, 56, 115-118.

Abdelrahman, E. M., (1990). Discussion on "A Least-squares Approach to Depth Determination from Gravity Data" by GUPTA, O.P., Geophysics, 55, 376-378.

Abdelrahman, E. M., Bayoumi, A. I., Abdelhady,Y. E., Gobash, M. M., and EL-Araby, H. M., (1989). Gravity Interpretation Using Correlation Factors between Successive Least -squares Residual Anomalies. Geophysics, 54, 1614-1621.
Abo-Ezz, E. R., and Essa, K. S., (2016). A least-squares minimization approach for model parameters estimate by using a new magnetic anomaly formula. Pure and Applied Geophysics, 173, 1265-1278.

Agarwal, B. N. P., Srivastava, S. (2008). FORTRAN codes to implement enhanced local wave number technique to determine location, depth and shape of the causative source using magnetic anomaly. Comput. Geosci., 34, 1843-1849.

Al-Garni, M. A., (2013). Inversion of residual gravity anomalies using neural network. Arab. J. Geosci., 6, 1509-1516.

Asfahani, J., and Tlas, M., (2012). Fair Function Minimization for Direct Interpretation of Residual Gravity Anomaly Profiles Due to Spheres and Cylinders. Pure and Applied Geophysics, 169, 157-165.

Asfahani, J., Tlas, M., (2007). A robust nonlinear inversion for the interpretation of magnetic anomalies caused by faults, thin dikes and spheres like structure using stochastic algorithms. Pure and Applied Geophysics, 164, 2023-2042.

Asfahani, J., Tlas, M., (2004). Nonlinearly Constrained Optimization Theory to Interpret Magnetic Anomalies Due to Vertical Faults and Thin Dikes. Pure and Applied Geophysics, 161, 203-219.

Bhattacharyya, B. K., (1965). Two-dimensional harmonic analysis as a tool for magnetic interpretation. Geophysics, 30, 829-857.

Biswas, A., Acharya, T. (2016). A Very Fast Simulated Annealing method for inversion of magnetic anomaly over semi-infinite vertical rod-type structure. Modeling Earth Systems and Environment, 2(4), 198.

Biswas, A., (2016a). A comparative performance of Least Square method and Very Fast Simulated Annealing Global Optimization method for interpretation of Self-Potential anomaly over 2-D inclined sheet type structure. Journal of the Geological Society of India, 88(4), 493-502.

Biswas, A., (2016b). Interpretation of gravity and magnetic anomaly over thin sheet-type structure using very fast simulated annealing global optimization technique. Modeling Earth Systems and Environment, 2(1), 30.

Biswas, A., Sharma, S. P. (2016a). Interpretation of Self-potential anomaly over 2-D inclined thick sheet structures and analysis of uncertainty using very fast simulated annealing global optimization. Acta Geodaetica et Geophysica, (DOI: 10.1007/s40328-0160176-2).

Biswas, A., Sharma, S. P., (2016b). Integrated geophysical studies to elicit the structure associated with Uranium mineralization around South Purulia She- 
ar Zone, India: A Review. Ore Geology Reviews, 72, 1307-1326.

Biswas, A., (2015). Interpretation of residual gravity anomaly caused by a simple shaped body using very fast simulated annealing global optimization. Geoscience Frontiers, 6(6), 875-893

Biswas, A., Sharma, S. P., (2015). Interpretation of self-potential anomaly over idealized body and analysis of ambiguity using very fast simulated annealing global optimization. Near Surface Geophysics, 13 (2), 179-195.

Biswas, A., Sharma, S. P., (2014a). Resolution of multiple sheet-type structures in self-potential measurement. Journal of Earth System Science, 123 (4), 809-825.

Biswas, A., Sharma, S. P. (2014b). Optimization of Self-Potential interpretation of 2-D inclined sheet-type structures based on Very Fast Simulated Annealing and analysis of ambiguity. Journal of Applied Geophysics, 105, 235-247.

Biswas, A., Mandal, A., Sharma, S. P., Mohanty, W. K., (2014a). Delineation of subsurface structure using self-potential, gravity and resistivity surveys from South Purulia Shear Zone, India: Implication to uranium mineralization. Interpretation, 2(2), T103-T110.

Biswas, A., Mandal, A., Sharma, S. P., Mohanty, W. K., (2014b). Integrating apparent conductance in resistivity sounding to constrain 2D Gravity modeling for subsurface structure associated with uranium mineralization across South Purulia Shear Zone. International Journal of Geophysics 2014, Article ID $691521,1-8$.

Biswas, A., (2013) Identification and resolution of ambiguities in interpretation of self-potential data: analysis and integrated study around South Purulia Shear Zone, India. Ph.D Thesis, Department of Geology and Geophysics, Indian Institute of Technology Kharagpur, 199 pp, doi: http: / / www.idr.iitkgp. ac.in/xmlui/ handle/123456789/3247

Bowin, C., Scheer, E. and Smith, W., (1986). Depth estimates from ratios of gravity, geoid and gravity gradient anomalies. Geophysics, 51, 123-136.

Dosso, S. E., Oldenburg, D. W., (1991). Magnetotelluric appraisal using simulated annealing. Geophysical Journal International, 106, 370-385.

Ekinci, Y. L., Balakaya, C., Gokturkler, G., Turan, S., (2016). Model parameter estimations from residual gravity anomalies due to simple-shaped sources using Differential Evolution Algorithm. Journal of Applied Geophysics, 129, 133-147.
Ekinci, Y. L., (2016). MATLAB-based algorithm to estimate depths of isolated thin dike-like sources using higher-order horizontal derivatives of magnetic anomalies. Springer Plus, 5(1), 1384.

Ekinci, Y. L., Yiğitbaş, E., (2015). Interpretation of gravity anomalies to delineate some structural features of Biga and Gelibolu peninsulas, and their surroundings (north-west Turkey). Geodin. Acta., 27 (4), 300-319.

Ekinci, Y. L., Ertekin, C., Yiğitbaş, E., (2013). On the effectiveness of directional derivative based filters on gravity anomalies for source edge approximation: synthetic simulations and a case study from the Aegean graben system (western Anatolia, Turkey). J. Geophys. Eng., 10, 035005.

Ekinci, Y.L., (2008). 2D focusing inversion of gravity data with the use of parameter variation as a stopping criterion. J. Balkan Geophys. Soc., 11 (1), 1-9.

Elawadi, E., Salem, A. and Ushijima, K., (2001). Detection of cavities from gravity data using a neural network. Exploration Geophysics, 32, 75-79.

Essa, K. S., (2013). New fast least-squares algorithm for estimating the best-fitting parameters due to simple geometric-structures from gravity anomalies. Journal of Advanced Research, 5(1), 57-65.

Essa, K. S., (2012). A fast interpretation method for inverse modelling of residual gravity anomalies caused by simple geometry. Journal of Geological Research, Volume 2012, Article ID 327037.

Essa, K. S., (2007). A simple formula for shape and depth determination from residual gravity anomalies. Acta Geophysica, 55, 182-190.

Fedi, M., (2007), DEXP: a fast method to determine the depth and the structural index of potential fields sources. Geophysics, 72(1), I1-I11.

Feng, J., Meng, X., Chen, Z., Zhang, S., (2014). Three-dimensional density interface inversion of gravity anomalies in the spectral domain. J. Geophys. Eng., 11, 035001.

Gay, S. P., (1965). Standard curves for the interpretation of magnetic anomalies over long horizontal cylinders. Geophysics, 30, 818-828.

Gay, S. P., (1963). Standard curves for the interpretation of magnetic anomalies over long tabular bodies. Geophysics, 28, 161-200.

Grant, R. S., West, G. F., (1965). Interpretation theory in applied geophysics. McGraw-Hill Book Co, New York.

Green, R. (1976). Accurate determination of the dip angle of a geological contact using the gravity method. Geophysical Prospecting, 24, 265-272. 
Gokturkler, G., Balkaya, C., (2012). Inversion of self-potential anomalies caused by simple geometry bodies using global optimization algorithms. Journal of Geophysics and Engineering, 9, 498-507.

Gupta, O. P., (1983). A Least-squares Approach to Depth Determination from Gravity Data: Geophysics, 48, 375-360.

Haney, M., Johnston, C., Li Y. Nabighian, M. (2003). Envelopes of 2D and 3D magnetic data and their relationship to the analytic signal: Preliminary results. SEG Expanded Abstract 22, 596.

Hartmann, R. R., Teskey, D. and Friedberg, I., (1971). A system for rapid digital aeromagnetic interpretation. Geophysics, 36, 891-918.

Hinze, W. J., Von Frese, R. R. B., Saad, A. H., (2013). Gravity and Magnetic Exploration.Cambridge University Press.

Ingber, L., Rosen, B., (1992). Genetic Algorithms and Very Fast Simulated Reannealing: A comparison. Mathematical and Computer Modeling, 16(11), 87-100.

Jacoby, W., Smilde, P. L., (2009). Gravity Interpretation, Fundamentals and Application of Gravity Inversion and Geological Interpretation.Springer-Verlag.

Jain, S., (1976). An automatic method of direct interpretation of magnetic profiles. Geophysics, 41, 531-541.

Juan, L. F. M., Esperanza, G. José, G. P. F. Á. Heidi, A. K. and César, O. M. P., (2010). PSO: A powerful algorithm to solve geophysical inverse problems: Application to a 1D-DC resistivity case. Journal of Applied Geophysics, 71, 13-25.

Kearey, P., Brooks, M., Hill, I., (2002). An Introduction to Geophysical Exploration. Blackwell Publishing, Oxford.

Kilty, T. K., (1983). Werner deconvolution of profile potential field data. Geophysics, 48, 234-237.

Last, B., Kubik, K., (1983). Compact gravity inversion. Geophysics, 48, 713-721.

Lines, L. R., and Treitel, S., (1984). A review of least-squares inversion and its application to geophysical problems. Geophysical Prospecting, 32, 159-186.

Li, Y. G., Oldenburg, D. W., (1996). 3-D inversion of magnetic data. Geophysics, 61, 394-408.

Li, Y. G., Oldenburg, D. W., (1998). 3-D inversion of gravity data. Geophysics, 63, 109-119.

McGrath, P. H., Hood, P. J., (1973). An automatic least-squares multi-model method for magnetic interpretation. Geophysics, 38(2), 349-358

McGrath, H., (1970). The dipping dike case: a computer curve-matching method of magnetic interpretation. Geophysics, 35(5), 831.

Mandal, A., Mohanty, W. K., Sharma, S. P., Biswas, A.,
Sen, J., Bhatt, A. K., (2015). Geophysical signatures of uranium mineralization and its subsurface validation at Beldih, Purulia District, West Bengal, India: A case study. Geophysical Prospecting, 63, 713-724.

Mandal, A., Biswas, A., Mittal, S., Mohanty, W. K., Sharma, S. P., Sengupta, D., Sen, J., Bhatt, A. K., (2013). Geophysical anomalies associated with uranium mineralization from Beldih mine, South Purulia Shear Zone, India. Journal of the Geological Society of India, 82(6), 601-606.

Mehanee, S., (2014). Accurate and efficient regularized inversion approach for the interpretation of isolated gravity anomalies. Pure and Applied Geophysics, 171 (8). 1897-1937.

Mehanee, S., Essa, K. S. (2015). 2.5D regularized inversion for the interpretation of residual gravity data by a dipping thin sheet: numerical examples and case studies with an insight on sensitivity and non-uniqueness. Earth, Planets and Space, 67, 130.

Mohan, N. L., Sundararajan N., Seshagiri Rao, S. V., (1982). Interpretation of some two-dimensional magnetic bodies using Hilbert transforms. Geophysics, 46, 376-387.

Mohan, N. L., Anandababu L., Roa, S., (1986). Gravity interpretation using Mellin transform: Geophysics, 52, 114-122.

Mosegaard, K., Tarantola, A., (1995). Monte Carlo sampling of solutions to inverse problems. Journal of Geophysical Research, 100 (B7), 12431-12447.

Nabighian, M. N., Grauch, V. J. S., Hansen, R. O., La Fehr, T. R., Li Y., Peirce, J. W., Phillips J. D. and Ruder M. E., (2005a). The his $\neg$ torical development of the magnetic method in exploration. Geophysics, 70, 33ND-61ND.

Nabighian, M. N., Ander, M. E., Grauch, V. J. S., Hansen, R. O., LaFehr, T. R., Li, Y., Pearson, W. C., Peirce, J. W., Philips, J. D., Ruder, M. E., (2005b). The historical development of the gravity method in exploration. Geophysics, 70, 63ND-89ND.

Nabighian, M. N. (1972). The analytic signal of two-dimensional magnetic bodies with polygonal crosssection: its properties and use for automated anomaly interpretation. Geophysics, 37, 507-517.

Nettleton, L. L., (1962). Gravity and Magnetics for Geologists and Seismologists. AAPG 46, 1815-1838.

Nettleton, L. L., (1971). Elementary Gravity and Magnetic for Geologists and Seismologists. SEG, Tulsa, OK.

Nettleton, L. L., (1976). Gravity and Magnetics in Oil Prospecting. McGraw-Hill Book Co, 1976.

Odegard, M. E. and Berg, J. W., (1965). Gravity Interpre- 
tation Using the Fourier Integral. Geophysics, 30, 424-438.

Pallero, J. L. G., Fernandez-Martinez, J. L., Bonvalot, S., Fudym, O., (2015). Gravity inversion and uncertainty assessment of basement relief via Particle Swarm Optimization. J. Appl. Geophys., 116, 180-191

Prakasa Rao, T. K. S., Subrahmanyan, M., Srikrishna Murthy, A., (1986). Nomograms for direct interpretation of magnetic anomalies due to long horizontal cylinders. Geophysics, 51, 2150-2159.

Ravat, D. (1996). Analysis of the Euler method and its applicability in environmental magnetic investigations. Journal of Environmental Engineering and Geophysics, 1, 229-238.

Reynolds, J. M., (1997). An Introduction to Applied and Environmental Geophysics. Wiley, Chichester.

Roest, W. R., Verhoef, J., Pilkington, M. (1992). Magnetic interpretation using 3D analytic signal. Geophysics, 57, 116-125.

Rothman, D. H., (1986). Automatic estimation of large residual statics correction. Geophysics, 51, 337-346.

Rothman, D. H., (1985). Nonlinear inversion, statistical mechanics and residual statics estimation. Geophysics, 50, 2784-2796.

Roy, L., Agarwal, B. N. P. and Shaw, R. K., (2000). A new concept in Euler deconvolution of isolated gravity anomalies. Geophysical Prospecting, 48, 559-575.

Salem, A., and Ravat, D., (2003), A combined analytic signal and Euler method (AN-EUL) for automatic interpretation of magnetic data. Geophysics, 68(6), 1952-1961.

Salem, A., Ravat, D., Smith, R. S., Ushijima, K. (2005). Interpretation of magnetic data using an enhanced local wave number (ELW) method. Geophysics, 70, L7-L12.

Sen, M. K., Stoffa, P. L., (2013). Global Optimization Methods in Geophysical Inversion.2nd eds. Cambridge Publisher, London.

Sen, M. K., Stoffa, P. L. (1996). Bayesian inference, Gibbs sampler and uncertainty estimation in geophysical inversion. Geophysical Prospecting, 44, 313-350.

Sharma, S. P., Biswas, A., (2013a). Interpretation of self-potential anomaly over a $2 \mathrm{D}$ inclined structure using very fast simulated-annealing global optimization-An insight about ambiguity. Geophysics, 78, WB3-15.

Sharma, S. P., Biswas, A. (2013b). A practical solution in delineating thin conducting structures and suppression problem in direct current resistivity sounding. Journal of Earth System Science, 122(4), 1065-1080.

Sharma, S. P., (2012). VFSARES- A very fast simulated annealing FORTRAN program for interpretation of 1-D DC resistivity sounding data from various electrode array. Computers and Geosciences, 42, 177-188.

Sharma, S. P., Biswas, A., (2011). Global nonlinear optimization for the estimation of static shift and interpretation of 1-D magnetotelluric sounding data. Annals of Geophysics, 54(3), 249-264.

Sharma, B., and Geldart, L. P., (1968). Analysis of gravity anomalies of two-dimensional faults using Fourier transforms. Geophysical Prospecting, 16, 77-93.

Sharma, S. P., Kaikkonen, P., (1999a). Appraisal of equivalence and suppression problems in 1-D EM and DC measurements using global optimization and joint inversion. Geophysical Prospecting, 47, 219-249.

Sharma, S. P., Kaikkonen, P., (1999b). Global Optimisation of Time Domain Electromagnetic Data Using Very Fast Simulated Annealing. Pure and Applied Geophysics, 155, 149-168.

Sharma, S. P., Kaikkonen, P., (1998). Two-dimensional nonlinear inversion of VLF-R data using simulated annealing. Geophysical Journal International, 133, 649-668.

Shaw, R. K. and Agarwal, B. N. P., (1990). The application of Walsh transforms to interpret gravity anomalies due to some simple geometrically shaped causative sources: A feasibility study. Geophysics, 55, 843-850.

Silva, J. B. C., (1989). Transformation of nonlinear problems into linear ones applied to the magnetic field of a two-dimensional prism. Geophysics, 54, 114-121.

Singh A., Biswas, A., (2016). Application of global particle swarm optimization for inversion of residual gravity anomalies over geological bodies with idealized geometries. Natural Resources Research, 25(3), 297-314.

Srivastava, S., Datta, D., Agarwal, B. N. P., Mehta, S., (2014). Applications of Ant Colony Optimization in determination of source parameters from total gradient of potential fields. Near Surface Geophysics, 12, 373-389.

Srivastava, S., Agarwal, B. N. P., (2010). Inversion of the amplitude of the two-dimensional analytic signal of the magnetic anomaly by the particle swarm optimization technique. Geophysical Journal International. 182, 652-662.

Srivastava, S., Agarwal, B. N. P. (2009). Interprettaion of self-potential anomalies by enhanced local wave number technique. Journal of Applied Geophysics, 68, 259-268.

Stanley, J.M., Green, R. (1976). Gravity gradients and interpretation of the truncated plate. Geophysics, 41, 1370-1376. 
Telford, W. M., Geldart, L. P., Sheriff, R. E., (1990). Applied Geophysics. Cambridge University Press.

Thompson, D. T., (1982). EULDPH-a new technique for making computer-assisted depth estimates from magnetic data. Geophysics, 47, 31-37.

Tlas, M., Asfahani, J., (2015). The Simplex Algorithm for Best-Estimate of Magnetic Parameters Related to Simple Geometric-Shaped Structures. Mathematical Geosciences, 47 (3), 301-316.

Tlas, M., Asfahani, J., (2011a). Fair function minimization for interpretation of magnetic anomalies due to thin dikes, spheres and faults. Journal of Applied Geophysics, 75, 237-243.

Tlas, M., Asfahani, J., (2011b). A new-best-estimate methodology for determining magnetic parameters related to field anomalies produced by buried thin dikes and horizontal cylinder-like structures. Pure and Applied Geophysics, 168, 861-870.

Tlas, M., Asfahani, J. and Karmeh, H., (2005). A versatile nonlinear inversion to interpret gravity anomaly caused by a simple geometrical structure. Pure and Applied Geophysics, 162, 2557-2571.

Vallee, M. A., Keating, P., Smith, R. S., St-Hilaire, C. (2004). Estimating depth and model type using the continuous wavelet transform of the magnetic data, Geophysics. 69, 191-199.

Zhao, L. S., Sen, M. K., Stoffa, P. L., Frohlich, C., (1996). Application of Very Fast Simulated Annealing to the Determination of the Crustal Structure beneath Tibet, Geophysical Prospecting, 125, 355-370.

Zhdanov, M. S., (2009). New advances in regularized inversion of gravity and electromagnetic data. Geophysical Prospecting, 57, 463-478.

${ }^{\star}$ Corresponding author: Arkoprovo Biswas Wadia Institute of Himalayan Geology (WIHG), General Mahadev Singh Road, Dehradun, Uttarakhand, India.; email: arkoprovo@gmail.com 